\title{
Effect of Ultraviolet Light Irradiation Combined with Riboflavin on Different Bacterial Pathogens from Ocular Surface Infection
}

\author{
Jing Shen, ${ }^{1}$ Qingfeng Liang, ${ }^{1}$ Guanyu Su, ${ }^{1}$ Yang Zhang, ${ }^{1}$ Zhiqun Wang, ${ }^{1}$ Hong Liang, ${ }^{1,2}$ \\ Christophe Baudouin, ${ }^{2,3}$ and Antoine Labbé ${ }^{1,2}$ \\ ${ }^{1}$ Beijing Institute of Ophthalmology, Beijing Tongren Eye Center, Beijing Tongren Hospital, \\ Capital Medical University and Beijing Ophthalmology \& Visual Sciences Key Laboratory, \\ National Engineering Research Center for Ophthalmology, Beijing 100005, China \\ ${ }^{2}$ INSERM, U968 and UMR_S 968, Institut de la Vision, University Paris 06 (UPMC) and CNRS, UMR_7210, 75012 Paris, France \\ ${ }^{3}$ Quinze-Vingts National Ophthalmology Hospital, Paris and Versailles Saint-Quentin-en-Yvelines University, Versailles, France
}

Correspondence should be addressed to Qingfeng Liang; lqflucky@163.com

Received 22 May 2017; Revised 2 August 2017; Accepted 29 August 2017; Published 12 October 2017

Academic Editor: Andrei B. Rubin

Copyright (C) 2017 Jing Shen et al. This is an open access article distributed under the Creative Commons Attribution License, which permits unrestricted use, distribution, and reproduction in any medium, provided the original work is properly cited.

In order to study Staphylococcus epidermis and Staphylococcus aureus in vitro viability after the exposure to ultraviolet (UV) light and riboflavin, twelve strains of Staphylococcus epidermis and twelve strains of Staphylococcus aureus were isolated from patients with bacterial keratitis. The growth situation of Staphylococcus epidermidis and Staphylococcus aureus under different experimental conditions was qualitatively observed. The number of colonies surviving bacteria was counted under different UV light power and different exposure time. The experiment showed that there was no inhibition effect on the growth of bacteria using riboflavin alone. In UV alone group and UV-riboflavin group, inhibition effect on the bacteria growth was found. The UV-riboflavin combination had better inhibition effect on bacteria than UV irradiation alone. The amount of bacteria in the UV-riboflavin group was decreased by $99.1 \% \sim 99.5 \%$ and $54.8 \% \sim 64.6 \%$ in the UV alone group, when the UV light power was $10.052 \mathrm{~mW} / \mathrm{cm}^{2}$ and the irradiation time was $30 \mathrm{~min}$. Moreover, with the increase of the UV power or irradiation time, the survival rates of bacteria were rapidly reduced. Compared with Staphylococcus aureus, Staphylococcus epidermis was more easily to be killed under the action of UV light combined with riboflavin.

\section{Introduction}

Infectious keratitis is a vision-threatening condition, which can be caused by bacteria, virus, fungus, parasites, and so forth. It was estimated that 6 million infectious corneal ulcers occurred annually in the 10 countries of southeast Asia with a total population of 1.6 billion [1]. In China, there are 3 million corneal blind patients, and infectious corneal blindness has an annual increase rate of 100,000 cases [2]. Bacterial keratitis is one of the most common ocular infections, which progresses rapidly and severely. If the appropriate antimicrobial treatment is delayed, it can lead to devastating complications, including blindness and loss of the eye. However, with the extensive use of broad spectrum antibiotic, recent studies have shown increasing evidence of resistance of microbes to antimicrobial agents. Antibiotic resistance can cause continued progression of the disease process despite the use of broad spectrum antibiotics and some more severe consequences [3-5]. The occurrence of antibiotic-resistant bacteria has prompted ophthalmologists to study the antimicrobial activity of additional biological, chemical, and physical sources as adjunctive or alternative therapies for bacterial keratitis.

Riboflavin and UV light-induced corneal collagen crosslinking (CXL) is a therapeutic procedure used in the visual sciences which is based on irradiation of the corneal surface with UV-A light $(370 \mathrm{~nm})$ in combination with the administration of riboflavin (vitamin B2) to increase the biomechanical strength of collagen fibrils of the cornea. The main objective of the CXL technique was initially to avoid the progression of keratoconus $[6,7]$. In some cases, CXL has also been proposed to treat infectious keratitis [8-10]. CXL is also one kind of photodynamic therapy (PDT) methods. 
PDT is a technique that utilizes reactive oxygen species (ROS) produced by a nontoxic dye or photosensitizer (PS) molecule in the presence of low intensity UV light or visible light to kill microbial cells. The PS molecule was excited from the ground state through the excited singlet state to a triplet state. Then, in the presence of oxygen, the PS undergoes reactions that produce reactive oxygen species to induce cell damage via oxidative stress [11-13]. Since the PS localizes to certain cells, only target cells in the irradiated area are damaged. Drug-resistant bacteria can be effectively eliminated by PDT [14] and there are no reports of microbes becoming resistant to PDT despite numerous attempts to induce resistance by repeated cycles of semilethal PDT and microbial regrowth [15].

In this study, we evaluated in vitro bactericidal effect of PDT on common ocular surface pathogens, Staphylococcus epidermis and Staphylococcus aureus. UV-riboflavin combination was selected to be used. The aim of this study is to develop a possible adjunctive or alternative therapy for bacterial keratitis.

\section{Materials and Methods}

\subsection{Materials}

2.1.1. Bacteria Isolation and Culture. Twelve isolates of Staphylococcus epidermis and 12 isolates of Staphylococcus aureus were selected for this study. All bacterial strains isolated from patients with bacterial keratitis were provided by the Department of Microbiology, Beijing Institute of Ophthalmology, Beijing Tongren Hospital. The bacterial strains stored in the glycerol tube were inoculated in a blood culture dish and resuscitated two times to a logarithmic growth phase. Then the bacterial colonies were scraped with an inoculation loop and placed into the bacterial diluents. After sufficient mixing, $0.5 \mathrm{McF}$ arland (MCF) turbidity standard bacterial suspensions were prepared using a turbid-meter (approximate bacteria concentration of $1 \sim 2 \times 10^{8}$ colonyforming units $/ \mathrm{ml}, \mathrm{CFU} / \mathrm{ml}$ ), which was used for the subsequent experiments.

2.1.2. Ultraviolet Light Source and Photosensitizer. The ultraviolet (UV) irradiation was performed with the LED point source (LAMPLIC UVEC-4, Blue Spectrum Rick Technology Co., Ltd., Shenzhen, China) with a wavelength of $370 \mathrm{~nm}$. Calibration of the light energy was carried out before each experiment to ensure that the output power density was in range of $0.58 \mathrm{~mW} / \mathrm{cm}^{2} \sim 10.052 \mathrm{~mW} / \mathrm{cm}^{2}$. The light power density was measured by optical power meter (VLP-2000, Femtosecond Technology Co., Ltd., Changchun, China). The diameter of light spot was about $7 \mathrm{~mm}$. In this experiment, the PS was riboflavin (Sigma-Aldrich Technology Co., Ltd., USA) which was dissolved into $2.5 \%$ wt solution of riboflavin with sterile phosphate buffered saline (PBS) and stored at $4^{\circ} \mathrm{C}$ in dark area.

\subsection{Methods}

2.2.1. Qualitative Observation of the Inhibition Effect on Bacteria In Vitro. Stock solution of riboflavin, $2.5 \%$ wt, was diluted

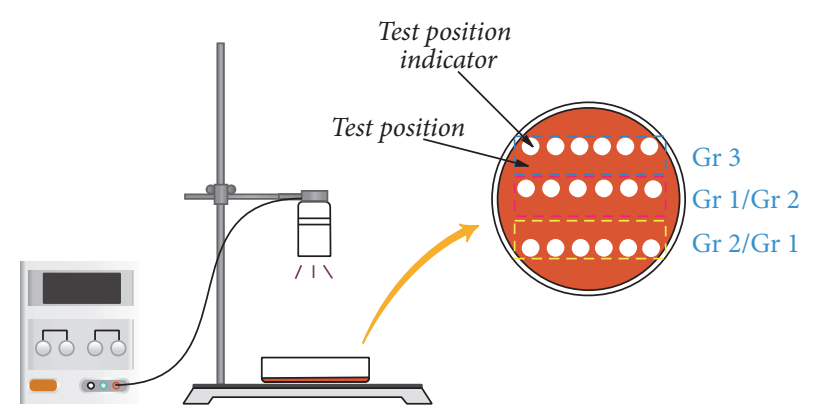

FIgURE 1: The experiment setup (Gr 1: UV-riboflavin group; Gr 2: control treated with UV alone group; Gr 3: control treated with riboflavin alone group).

to $0.1 \%$ wt with sterile PBS. In this experiment, four different samples were prepared which are UV-riboflavin treated sample (Group 1), control treated with UV alone (Group 2), control treated with riboflavin alone (Group 3), and control untreated. $200 \mu \mathrm{L}$ bacterial suspension (0.5 MCF) was aseptically transferred into the $9 \mathrm{~cm}$ blood agar plates with properly labeled test positions of control samples and UV-riboflavin treated sample. $10 \mu \mathrm{L}$ diluent riboflavin solution $(0.1 \% \mathrm{wt})$ was added in each labeled test position of UV-riboflavin treated sample and riboflavin alone treated control sample. Before exposure to UV light, the samples to be irradiated were incubated in dark for $20 \mathrm{~min}$. $370 \mathrm{~nm}$ UV light was used to irradiate UV-riboflavin treated sample and UV alone treated sample. The samples were irradiated by different power of UV light $\left(10.052 \mathrm{~mW} / \mathrm{cm}^{2}, 7.299 \mathrm{~mW} / \mathrm{cm}^{2}, 5.273 \mathrm{~mW} / \mathrm{cm}^{2}\right.$, $2.474 \mathrm{~mW} / \mathrm{cm}^{2}, 1.065 \mathrm{~mW} / \mathrm{cm}^{2}$, and $0.58 \mathrm{~mW} / \mathrm{cm}^{2}$, resp.) for $20 \mathrm{~min}$. Also irradiation time of $2 \mathrm{~min}, 5 \mathrm{~min}, 7 \mathrm{~min}, 10 \mathrm{~min}$, $15 \mathrm{~min}, 20 \mathrm{~min}$, and $30 \mathrm{~min}$ was taken for Staphylococcus epidermis and Staphylococcus aureus when the light power density was fixed at $5.273 \mathrm{~mW} / \mathrm{cm}^{2}$. The entire experimentation was carried out in the dark box to avoid the influence of the ambient light. After irradiation, the experimental samples were incubated at $37^{\circ} \mathrm{C}$ for 48 hours. And then the growth situation of bacteria in different groups was observed and recorded. The detailed experiment setup is shown in Figure 1.

\subsubsection{Bacteria Inactivation Experiments In Vitro}

(1) Inhibition Effect of Different UV Light Energy. 0.5 MCF bacteria suspensions of Staphylococcus epidermis and Staphylococcus aureus diluted into 1:10 with PBS were taken as UV alone group samples. $100 \mu \mathrm{L}$ bacteria suspensions (0.5 $\mathrm{MCF})$ and $400 \mu \mathrm{L}$ riboflavin solution (2.5\% wt) were taken into $500 \mu \mathrm{L}$ PBS as UV-riboflavin group samples. The initial population densities of experimental samples were both maintained at about $10^{7} \mathrm{CFU} / \mathrm{ml}$ and the concentration of riboflavin solution was about $0.1 \%$ wt.

$150 \mu \mathrm{L}$ aliquots of the sample solutions were subjected to 96-well culture plates (Costar Corning, New York, USA). The inside diameter of the well is about $5 \mathrm{~mm}$. The distance of light source to surface of solution was $5 \mathrm{~mm}$. And the light spot diameter was about $7 \mathrm{~mm}$ at this distance, which was larger than the well and enabled satisfying irradiation 


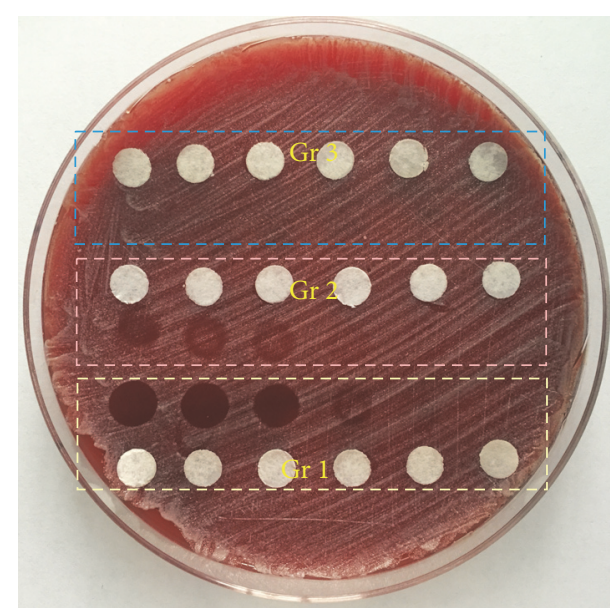

(a)

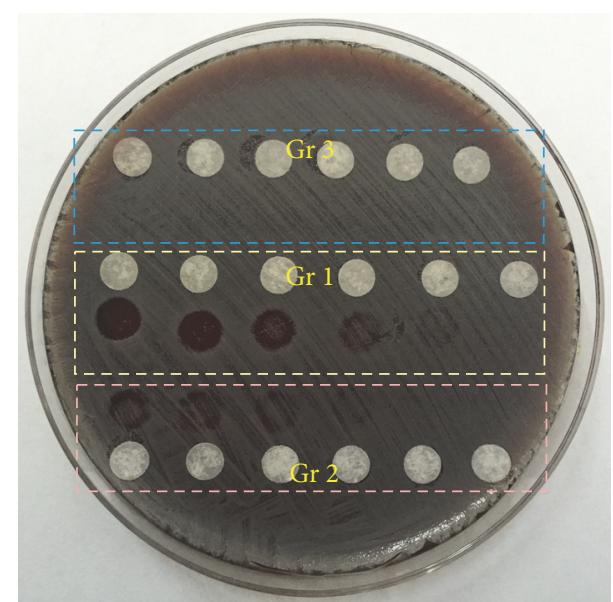

(b)

Figure 2: The bactericidal effect under the same irradiation time $(20 \mathrm{~min})$ and different light power ((a) Staphylococcus epidermis, (b) Staphylococcus aureus). The power density of UV light from left to right was $10.052 \mathrm{~mW} / \mathrm{cm}^{2}, 7.299 \mathrm{~mW} / \mathrm{cm}^{2}, 5.273 \mathrm{~mW} / \mathrm{cm}^{2}, 2.447 \mathrm{~mW} / \mathrm{cm}^{2}$, $1.065 \mathrm{~mW} / \mathrm{cm}^{2}$, and $0.58 \mathrm{~mW} / \mathrm{cm}^{2}$. White paper used to mark the location of the test site. (Gr 1: UV-riboflavin group; Gr 2: control treated with UV alone group; Gr 3: control treated with riboflavin alone group.)

of suspension surface with UV light. The illumination was conducted in dark box to prevent photosensitization of riboflavin from background visible light. The energy density was $1.065 \mathrm{~mW} / \mathrm{cm}^{2}, 2.474 \mathrm{~mW} / \mathrm{cm}^{2}, 5.273 \mathrm{~mW} / \mathrm{cm}^{2}$, and $7.299 \mathrm{~mW} / \mathrm{cm}^{2}$, respectively, and the irradiation time was $20 \mathrm{~min}$. For the control group samples, the suspensions in 96-well plates were kept in the dark at room temperature for $20 \mathrm{~min}$.

(2) Inhibition Effect of Different Irradiation Time. The experimental samples were prepared as described above (see Section 2.2.2(1)). In this part of experiment, the UV light energy was chosen as $5.273 \mathrm{~mW} / \mathrm{cm}^{2}$. The irradiation time was $5 \mathrm{~min}, 10 \mathrm{~min}, 20 \mathrm{~min}$, and $30 \mathrm{~min}$, respectively. After the experiment, the counting of the number of bacterial colonies and the calculation of survival fractions were conducted as mentioned below.

(3) Cell Concentration Determination and Survival Fraction Calculation. After the experimental treatments, aliquots $(100 \mu \mathrm{L})$ were withdrawn from each well and serially diluted 10 -fold with PBS. Ten microlitres from each dilution mixture was streaked onto blood agar plates (Tianjin Jinzhang Technique Development Co., China) in triplicate [16]. After incubation for 48 hours at $37^{\circ} \mathrm{C}$, bacterial colonies were counted.

The survival fraction was calculated according to the equation N/No., where No. is the number of CFU per $\mathrm{mL}$ of bacteria without being treated and $N$ is the number of CFU per $\mathrm{mL}$ of bacteria treated with UV light and riboflavin. All results were presented as means \pm standard deviation (SD) of at least three independent experiments and each was measured in triplicate.

2.3. Statistical Analysis. Statistical analyses were performed by SPSS software (version 18.0, SPSS Inc., Chicago, Illinois,
USA). Experimental data were confirmed to be of normal distribution by the $K-S$ test. Descriptive statistics were used to summarize the data in multiplex analyses. The results were shown as the means \pm SD. The statistical significance between groups was determined using two-way analysis of variance (ANOVA). $P<0.05$ were considered to be statistically significant.

\section{Results}

3.1. Qualitative Observation of the Inhibition Effect on Bacteria. The growth situation of Staphylococcus epidermidis and Staphylococcus aureus under different experimental conditions is shown in Figures 2 and 3. Figure 2(a) shows that the growth situation of Staphylococcus epidermidis in different experimental groups changed with different light energy irradiated. Figure 2(b) shows the changes in bacterial growth of Staphylococcus aureus in different experimental groups exposed to UV light with different energy. The irradiation time is settled as $20 \mathrm{~min}$ for both of the bacterial species. Obviously, there is no inhibitory effect on the growth of bacteria in the control treated with riboflavin alone groups for both kinds of bacteria. The number of bacteria in the control treated with UV group decreases gradually with the increase of the UV light energy. However, UV-riboflavin treated group shows significant decrease in the viability when compared to all other control samples. Effect of bacterial killing is more pronounced with the increase of UV light energy in both of these bacterial species. Compared with Group 2, fewer bacteria survive in Group 1 exposed on UV light with the same energy. As shown in Figure 2(a), when the light power is greater than or equal to $5.273 \mathrm{~mW} / \mathrm{cm}^{2}$, the bacteria could not continue to grow with the presence of riboflavin, indicating that all the bacteria are inactivated.

Figure 2(b) shows the growth of Staphylococcus aureus under different experimental conditions, which is similar 


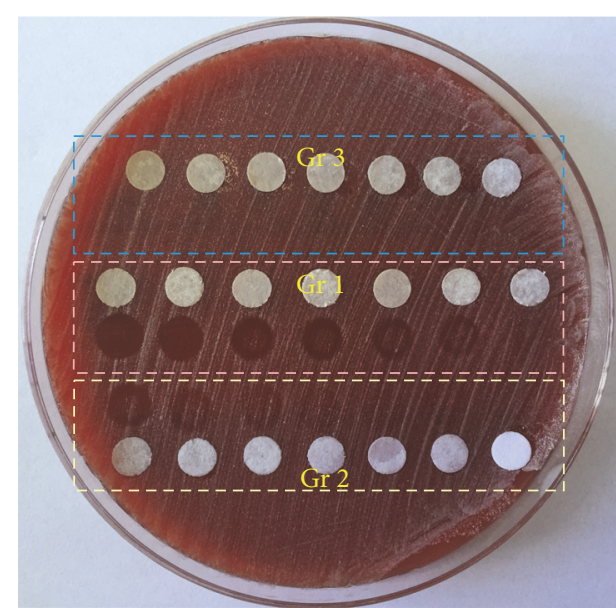

(a)

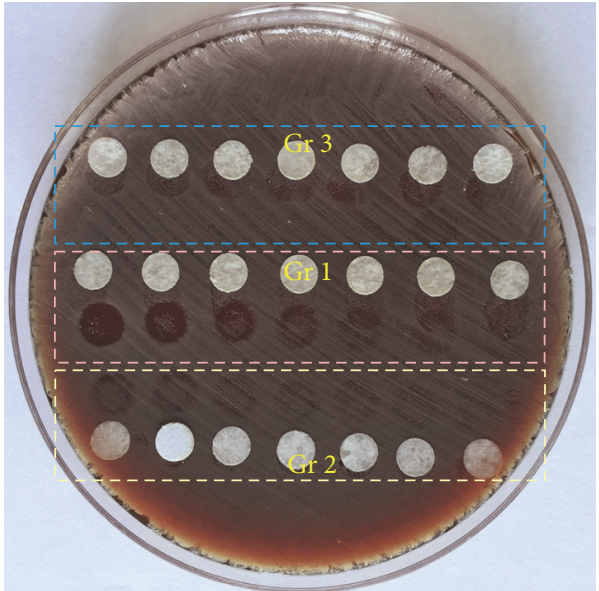

(b)

FIGURE 3: The bactericidal effect under the same light power density $\left(5.273 \mathrm{~mW} / \mathrm{cm}^{2}\right)$ and different irradiation time ((a) Staphylococcus epidermis, (b) Staphylococcus aureus). The irradiation time of UV light from left to right was $30 \mathrm{~min}, 20 \mathrm{~min}, 15 \mathrm{~min}, 10 \mathrm{~min}, 7 \mathrm{~min}, 5 \mathrm{~min}$, and $2 \mathrm{~min}$. White paper used to mark the location of the test site. (Gr 1: UV-riboflavin group; Gr 2: control treated with UV alone group; Gr 3: control treated with riboflavin alone group.)

to that of Staphylococcus epidermidis. In Group 3, no bacteriostatic region is produced on the medium, and the bacteria grow normally as control untreated group. There is an obvious reduction of the bacteria number in Group 1 and Group 2. Moreover, the survival of bacteria in the light area became less with the increase of UV intensity. By comparison of Group 1 and Group 2, it is also found that more bacteria were killed at the same light power irradiation when the riboflavin is present. However, to achieve the same efficacy of killing, Staphylococcus aureus required higher light energy than Staphylococcus epidermidis, as shown in Figures 2(a) and 2(b).

Figure 3(a) shows that the growth situation of Staphylococcus epidermidis in different experimental groups changed with the irradiation time. The changes in bacterial growth of Staphylococcus aureus in different experimental groups after being exposed to UV light for different time were shown in Figure 3(b). In this part of experiment, the power density of UV light is kept with $5.273 \mathrm{~mW} / \mathrm{cm}^{2}$. As shown in Figures $3(a)$ and 3(b), the bacteria are in normal growth for both of the bacterial species in Group 3. UV-riboflavin treated groups in both bacterial species show significant decrease in the viability when compared with the control group treated with UV only at the same irradiation time. Moreover, along with the extended irradiation time, the bacteria-killing effect is improved significantly. However, compared to Staphylococcus epidermidis, Staphylococcus aureus is more difficult to eliminate under the same experimental condition. In order to kill the same amount of bacteria, Staphylococcus aureus needs more time to be exposed with the UV light.

\subsection{Quantitive Analysis of the Inhibition Effect on Bacteria.}

The quantitive comparison test was conducted in the four experimental groups. The power density of UV light was $10.052 \mathrm{~mW} / \mathrm{cm}^{2}$ and the irradiation time was $30 \mathrm{~min}$. The concentration of riboflavin solution was about $0.1 \%$ wt. The

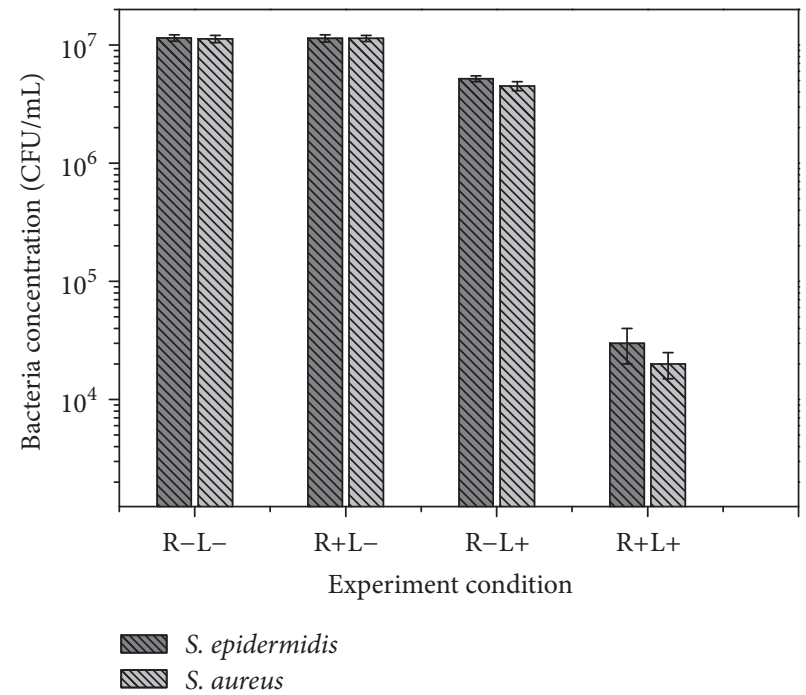

Figure 4: The number of survival bacterial colonies after different bactericidal experiment (R: riboflavin; L: UV light) to Staphylococcus aureus and Staphylococcus epidermis (light power density: $10.052 \mathrm{~mW} / \mathrm{cm}^{2}$, irradiation time: $30 \mathrm{~min}$ ).

results in Figure 4 showed that the colony number of Staphylococcus epidermidis and Staphylococcus aureus in different experimental groups was statistically significant. The colony number of the two bacteria in the control treated with UV alone group was significantly lower than that in the control untreated group and the difference was statistically significant $(P<0.05)$. The colony number of the two bacteria in the UVriboflavin treated group was also significantly lower than that in the control untreated group $(P<0.05)$. Compared with the control untreated group, the amount of bacteria in the control treated with UV alone group decreased by $54.8 \%$ $64.6 \%$, and the amount of bacteria in the UV-riboflavin treated 
TABLE 1: Survival fraction of Staphylococcus epidermis and Staphylococcus aureus with different UV light energy in the UV-riboflavin group (irradiation time: $20 \mathrm{~min}$ ).

\begin{tabular}{lcc}
\hline Power density $\left(\mathrm{mW} / \mathrm{cm}^{2}\right)$ & Survival fraction of S. epidermidis $(\%)$ & Survival fraction of S. aureus $(\%)$ \\
\hline 0 & 100 & 100 \\
1.065 & $55.1 \pm 3.6$ & $70.5 \pm 2.7$ \\
2.474 & $43.5 \pm 2.2$ & $56 \pm 2.3$ \\
5.273 & $38.1 \pm 1.9$ & $43.3 \pm 1.7$ \\
7.299 & $28.3 \pm 1.6$ & $32.6 \pm 1.5$ \\
\hline
\end{tabular}

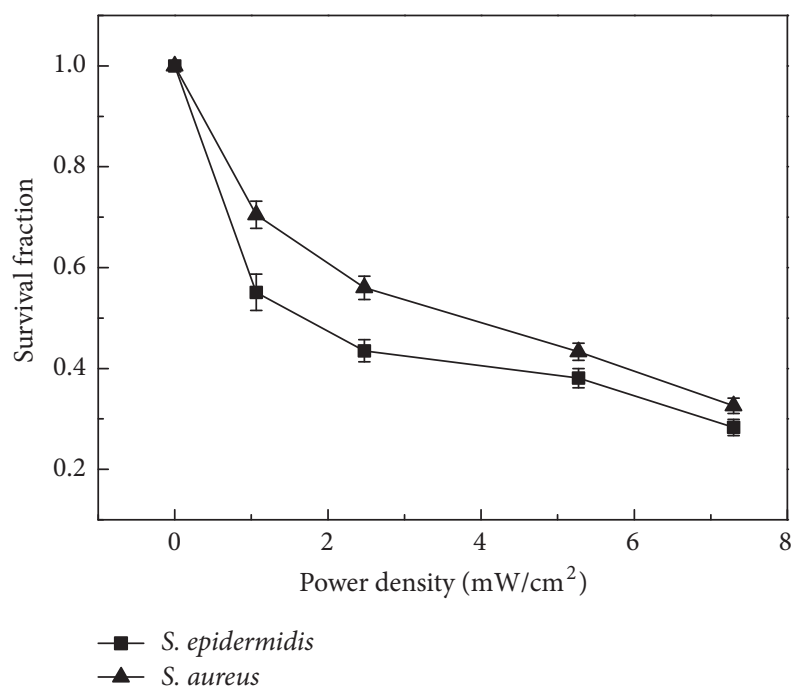

FIGURE 5: Survival fraction of Staphylococcus epidermis and Staphylococcus aureus with different UV power in the UV-riboflavin group (irradiation time: $20 \mathrm{~min}$ ).

group decreased by $99.1 \% \sim 99.5 \%$. There was no significant difference in the amount of bacteria between the control treated with riboflavin only and the normal control untreated group in all bacterial strains $(P>0.05)$.

In this portion of the study, PDT was conducted under the varying conditions in order to further understand the bactericidal efficacy. The survival fractions of Staphylococcus epidermis and Staphylococcus aureus under different UV light power were calculated and shown in Figure 5. With the increase of the UV light power, the survival fractions of both of the bacteria were rapidly reduced. However, it is clear that the survival fraction of Staphylococcus epidermis is lower than that of Staphylococcus aureus using the same UV light power. When the UV light power was $1.065 \mathrm{~mW} / \mathrm{cm}^{2}$, about $50 \%$ of Staphylococcus epidermis was killed after 20 min irradiation, but $70 \%$ of Staphylococcus aureus still survived. With further increase in light power, the survival fraction of the two bacteria decreased correspondingly, but the difference between them still existed. With the increase of UV light power, the difference of the survival fraction between them became smaller. The details of survival fraction of Staphylococcus epidermis and Staphylococcus aureus under different UV light power were listed in Table 1.

The survival fractions of Staphylococcus epidermis and Staphylococcus aureus with different irradiation time were

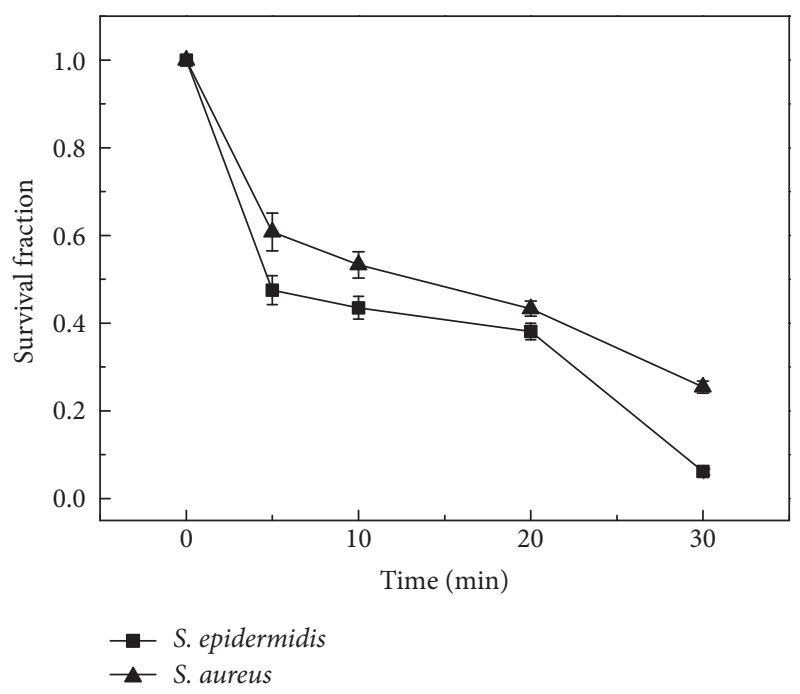

FIgURE 6: Survival fraction of Staphylococcus epidermis and Staphylococcus aureus under different UV irradiation time in the UVriboflavin group (light power density: $5.273 \mathrm{~mW} / \mathrm{cm}^{2}$ ).

calculated and shown in Figure 6. The survival fractions for both of the bacteria were rapidly reduced with extending the irritation time. Even with only $5 \mathrm{~min}$ irradiation, the survival fraction of Staphylococcus epidermis reduced to $45 \%$, and the survival fraction of Staphylococcus aureus reduced to $60 \%$. There was still difference in the survival fraction between the two kinds of bacteria. Compared with Staphylococcus aureus, Staphylococcus epidermis was more easily to be killed under the action of UV light combined with riboflavin. The details of survival fraction of Staphylococcus epidermis and Staphylococcus aureus with different time irradiation were also listed in Table 2.

\section{Discussions}

The UV light as a therapeutic tool has been found around for thousands of years. Raab used PDT for antimicrobial studies more than 100 years ago, but this kind of research was not to be continued and the focus had shifted to its antitumor mechanisms and clinical applications [17-19]. Oppositely, the progress of PDT for antimicrobial treatment was very slow. In recent years, along with the emergence of drug-resistant bacteria, the researchers began to reexamine the value of PDT in local resistance to infection [20]. 
TABLE 2: Survival fraction of Staphylococcus epidermis and Staphylococcus aureus under different UV irradiation time in the UV-riboflavin group (UV light energy: $5.273 \mathrm{~mW} / \mathrm{cm}^{2}$ ).

\begin{tabular}{lcr}
\hline Irradiation time $(\mathrm{min})$ & Survival fraction of S. epidermidis $(\%)$ & Survival fraction of S. aureus $(\%)$ \\
\hline 0 & 100 & 100 \\
5 & $47.5 \pm 3.3$ & $60.8 \pm 4.3$ \\
10 & $43.5 \pm 2.6$ & $53.3 \pm 3.0$ \\
20 & $38.1 \pm 1.9$ & $43.3 \pm 1.7$ \\
30 & $6.2 \pm 0.7$ & $25.4 \pm 1.4$ \\
\hline
\end{tabular}

In the last decade, the research of PDT antimicrobial effects was launched and has made more progress. At the beginning, the studies focused on the disinfection of whole blood and blood components [21]. The present study found that PDT can effectively kill multidrug-resistant strains, which is even more effective than some antibiotics. Moreover, bacteria were difficult to produce resistance to PDT. From our study, the amount of bacteria in the UV-riboflavin group was decreased by $99.1 \% \sim 99.5 \%$, and the bacterial count was decreased by $54.8 \% \sim 64.6 \%$ in the control UV alone group. With the increase of the UV intensity, the survival rates of bacteria were rapidly reduced. The photosensitizer, like riboflavin, could be used to inactivate bacteria combined with UV light, whose mechanism was involved in the cytotoxic effect of photosensitizer by light induced photosensitization. This cytotoxic effect of photosensitizer has been attributed to the production of singlet oxygen, superoxide ions, and hydroxyl radicals $[22,23]$. These cytotoxic reactive oxygen species are primarily involved in cellular death of bacteria, which is either caused by the damage of their DNA or the lysis of their cell wall $[20,21]$. Through the study of sterilization for Staphylococcus aureus using hematoporphyrin as photosensitizer, Bertoloni et al. [24] found that the cell membrane was the primary target. The electrophoresis of whole-cell protein analysis showed that cytoplasmic proteins had no change. But cell membrane proteins were changed, which would cause cell inactivation. The damage of DNA appeared as the break of single-stranded DNA and double-stranded DNA and the disappearance of plasmid superhelix fragment [25-27]. Kumar et al. [28] found that photosensitizer riboflavin could combine with nucleic acid of bacteria and further damage their DNA by the photochemical reactions. The hydroxyl generated by nucleic acid could result in the base damage and the increase of DNA degradation. Some studies also indicated that it was different to eliminate the Gram-positive bacteria and Gram-negative bacteria. This has been attributed to the complex cell-wall structure of Gram-negative species compared to Gram-positive ones with lesser photosensitizer and light penetrating the cell-wall structure [29].

In our study, it was found that the susceptibility of Staphylococcus epidermidis and Staphylococcus aureus for PDT was different. Although Staphylococcus epidermidis and Staphylococcus aureus belong to the Staphylococcus and are both Gram-positive bacteria, the survival rate of Staphylococcus epidermis was lower than that of Staphylococcus aureus after being irradiated by the same UV light parameters. The reason may be related to the formation of bacterial biofilm. Previous studies have shown that bacteria can form a multibacterial complex during growth, consisting of bacteria and their secreted extracellular polysaccharides, known as the bacterial biofilm (BBF) $[30,31]$. BBF can protect the internal bacteria from bactericide and escape from the host immune killer, so BBF is more difficult to eradicate than isolated bacteria. Staphylococcus epidermis and Staphylococcus aureus are able to form BBF, but the ability of two bacteria to form bacterial biofilm is not the same. Compared to Staphylococcus epidermis, Staphylococcus aureus is more likely to form multibacterial complex, which resists penetration of photosensitizer or light into the inside. Hence, in order to achieve the same bactericidal efficacy, higher light energy or longer irradiation time could be required. Further research should be conducted to reveal their mechanism.

In conclusion, our study revealed that common pathogens of ocular surface could be effectively inactivated. However, because of the different susceptibility in PDT treatment, the irradiation parameters should be adjusted according to the different pathogenic bacteria. PDT treatment can prove to be effective for cornea infections. A further insight in PDT with in vivo experiment is required to ensure the effectiveness of the antimicrobial PDT.

\section{Disclosure}

An earlier version of this work was partially presented as a poster at the 22nd Congress of Chinese Ophthalmological Society and ARVO Congress, 2017.

\section{Conflicts of Interest}

No conflicts of interest exist for any author.

\section{Acknowledgments}

This work was supported by National Natural Science Foundation of China (no. 81470607). All of the authors gratefully acknowledge the financial support.

\section{References}

[1] J. P. Whitcher and M. Srinvasan, "Corneal ulceration in developing world: a silent epidemic," British Journal of Ophthalmology, vol. 81, pp. 622-623, 1997.

[2] X. Song, L. Xie, X. Tan et al., "A multi-center, cross-sectional study on the burden of infectious keratitis in China," PLOS ONE, vol. 9, no. 12, p. el13843, 2014. 
[3] S. C. Xu, J. Chow, and J. Liu, "Risk factors for visual impairment associated with corneal diseases in southern China," Clinical Ophthalmology, pp. 777-782, 2016.

[4] M. Green, A. Apel, and F. Stapleton, "Risk factors and causative organisms in microbial keratitis," Cornea, vol. 27, no. 1, pp. 22$27,2008$.

[5] H. C. Neu, “The crisis in antibiotic resistance," Science, vol. 257, no. 5073, pp. 1064-1073, 1992.

[6] B. J. Dahl, E. Spotts, and J. Q. Truong, "Corneal collagen crosslinking: an introduction and literature review," Optometry, vol. 83, no. 1, pp. 33-42, 2012.

[7] D. P. O'Brart, T. Q. Kwong, P. Patel, R. J. McDonald, and N. A. O'Brart, "Long-term follow-up of riboflavin/ultraviolet A $(370 \mathrm{~nm})$ corneal collagen cross-linking to halt the progression of keratoconus," British Journal of Ophthalmology, vol. 97, no. 4, pp. 433-437, 2013.

[8] H. P. T. M. Iseli, F. Hafezi, J. Kampmeier, and T. Seiler, "Ultraviolet a/riboflavin corneal cross-linking for infectious keratitis associated with corneal melts," Cornea, vol. 27, no. 5, pp. 590-594, 2008.

[9] K. M. J. Makdoumi and S. Crafoord, "Infectious keratitis treated with corneal crosslinking," Cornea, vol. 29, no. 12, pp. 1353-1358, 2010.

[10] H. Moren, J. Mortensen, and A. Ohrstrom, "Riboflavin and ultraviolet a collagen crosslinking of the cornea for the treatment of keratitis," Cornea, vol. 29, no. 1, pp. 102-104, 2010.

[11] M. Wainwright, "Photodynamic antimicrobial chemotherapy (PACT)," Journal of Antimicrobial Chemotherapy, vol. 42, no. 1, pp. 13-28, 1998.

[12] G. Jori, C. Fabris, M. Soncin et al., "Photodynamic therapy in the treatment of microbial infections: basic principles and perspective applications," Lasers in Surgery and Medicine, vol. 38, no. 5, pp. 468-481, 2006.

[13] R. F. Donnelly, P. A. McCarron, and M. M. Tunney, "Antifungal photodynamic therapy," Microbiological Research, vol. 163, no. 1, pp. 1-12, 2008.

[14] T. Maisch, "A new strategy to destroy antibiotic resistant microorganisms: antimicrobial photodynamic treatment," Mini-Reviews in Medicinal Chemistry, vol. 9, no. 8, pp. 974-983, 2009.

[15] F. Giuliani, M. Martinelli, A. Cocchi, D. Arbia, L. Fantetti, and G. Roncucci, "In Vitro resistance selection studies of RLP068/Cl, a new $\mathrm{Zn}$ (II) phthalocyanine suitable for antimicrobial photodynamic therapy," Antimicrobial Agents and Chemotherapy, vol. 54, no. 2, pp. 637-642, 2010.

[16] B. D. Jett, K. L. Hatter, and M. M. Huycke, "Simplified agar plate method for quantifying viable bacteria," Biotechniques, vol. 23, pp. 648-650, 1997.

[17] J. Moan and Q. Peng, "An outline of the hundred-year history of PDT," Anticancer Research, vol. 23, pp. 3591-3600, 2003.

[18] T. Maisch, R. M. Szeimies, G. Jori, and C. Abels, "Antibacterial photodynamic therapy in dermatology," Photochemical \& Photobiological Sciences, vol. 3, no. 10, pp. 907-917, 2004.

[19] D. E. Dolmans, D. Fukumura, and R. K. Jain, "Photodynamic therapy for cancer," Nature Reviews Cancer, vol. 3, pp. 380-387, 2003.

[20] T. Maisch, "Revitalized strategies against multi-resistant bacteria: antimicrobial photodynamic therapy and bacteriophage therapy," Anti-Infective Agents in Medicinal Chemistry, vol. 6, no. 2, pp. 145-150, 2007.
[21] M. Wainwright, "The emerging chemistry of blood product disinfection," Chemical Society Reviews, vol. 31, no. 2, pp. 128 136.

[22] F. Corbin, "Pathogen inactivation of blood components: Current status and introduction of an approach using riboflavin as a photosensitizer," International Journal of Hematology, vol. 76, no. S2, pp. 253-257, 2002.

[23] K. Sato, H. Taguchi, and T. Maeda, "The primary cytoxicity in ultraviolet-a-irradiated riboflavin solution is derived from hydrogen peroxide," Journal of Investigative Dermatology, vol. 105, pp. 608-612, 1995.

[24] G. Bertoloni, F. M. Lauro, G. Cortella, and M. Merchat, "Photosensitizing activity of hematoporphyrin on Staphylococcus aureus cells," Biochimica et Biophysica Acta-General Subjects, vol. 1475, no. 2, pp. 169-174, 2000.

[25] P. A. and H. F., "Light activated compounds as antimicrobial agents - patently obvious?" Recent Patents on Anti-Infective Drug Discovery, vol. 1, no. 2, pp. 181-199, 2006.

[26] B. C. Wilson and M. S. Patterson, "The physics, biophysics and technology of photodynamic therapy," Physics in Medicine and Biology, vol. 53, no. 9, pp. R61-R109, 2008.

[27] X. J. Fu, Y. Q. Zhu, Y. B. Peng et al., "Enzyme activated photodynamic therapy for methicillin-resistant Staphylococcus aureus infection both inv itro and in vivo," Journal of Photochemistry and Photobiology B: Biology, vol. 136, pp. 72-80, 2014.

[28] V. Kumar, O. Lockerbie, S. D. Keil et al., "Riboflavin and UV-Light based pathogen reduction: extent and consequence of DNA damage at the molecular level," Photochemistry and Photobiology, vol. 80, no. 1, pp. 15-21, 2004.

[29] M. R. Hamblin and T. Hasan, "Photodynamic therapy: a new antimicrobial approach to infectious disease?" Photochemical and Photobiological Sciences, vol. 3, no. 5, pp. 436-450, 2004

[30] S. H. Abidi, S. K. Sherwani, T. R. Siddiqui, A. Bashir, and S. U. Kazmi, "Drug resistance profile and biofilm forming potential of Pseudomonas aeruginosa isolated from contact lenses in Karachi-Pakistan," BMC Ophthalmology, vol. 13, no. 1, 2013.

[31] L. Wiley, D. R. Bridge, L. A. Wiley, J. V. Odom, T. Elliott, and J. C. Olson, "Bacterial biofilm diversity in contact lens-related disease: emerging role of Achromobacter, Stenotrophomonas, and Delftia," Investigative Opthalmology \& Visual Science, vol. 53, no. 7, pp. 3896-3905, 2012. 

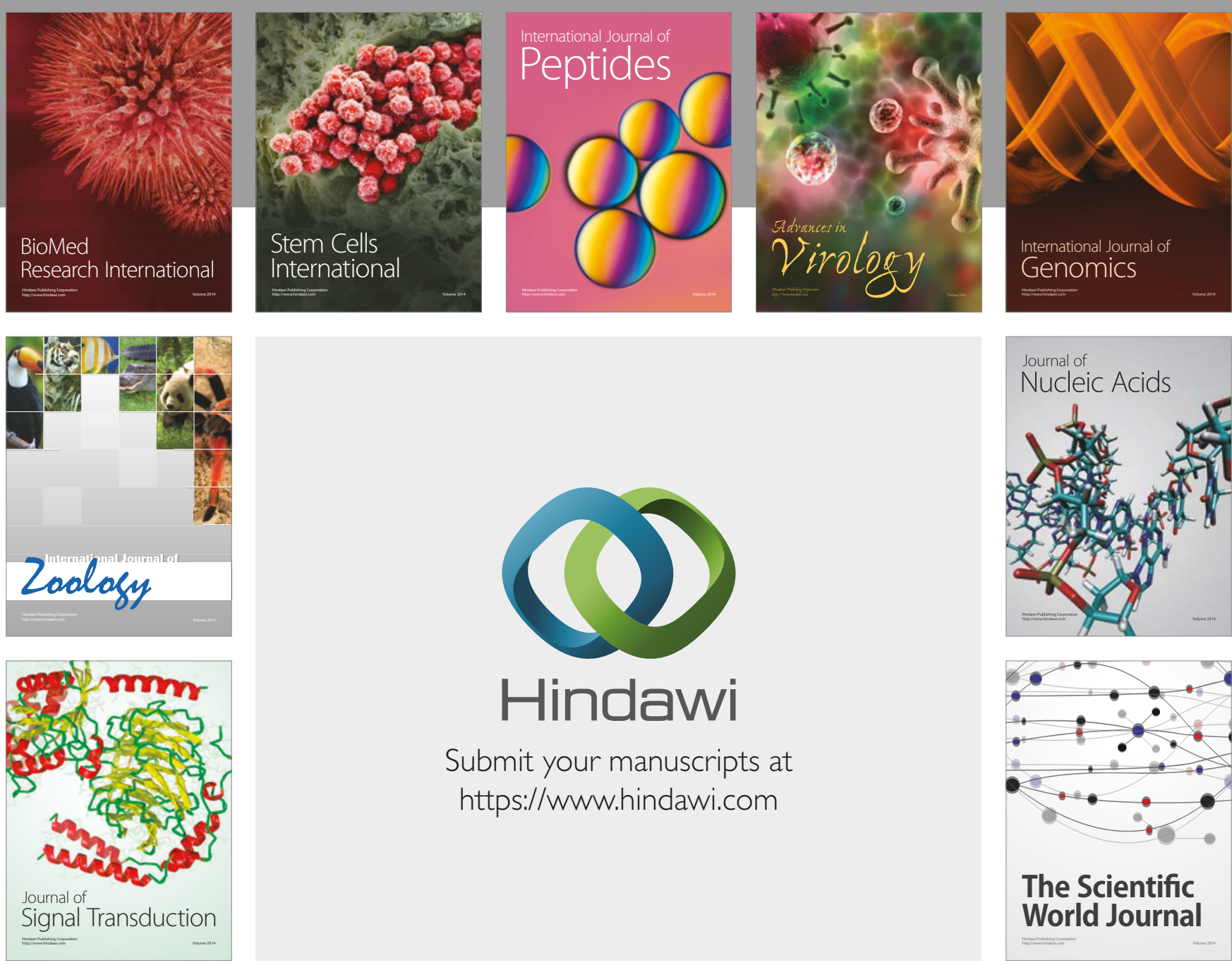

Submit your manuscripts at

https://www.hindawi.com
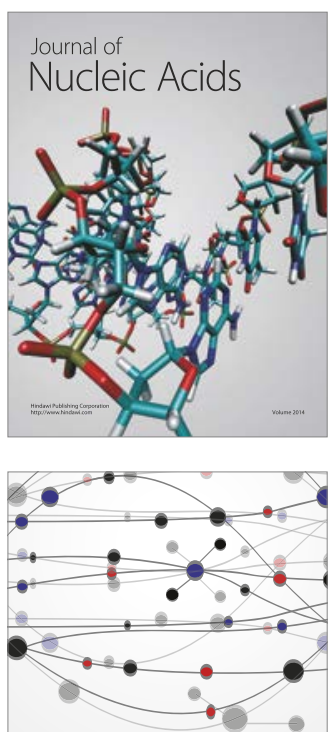

The Scientific World Journal

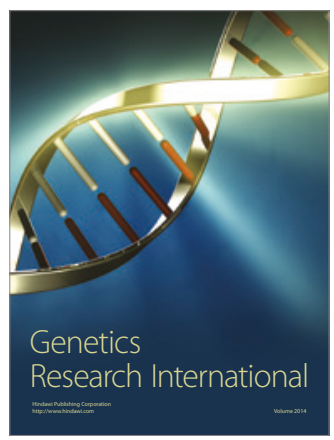

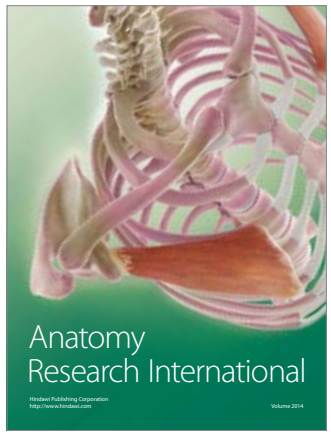

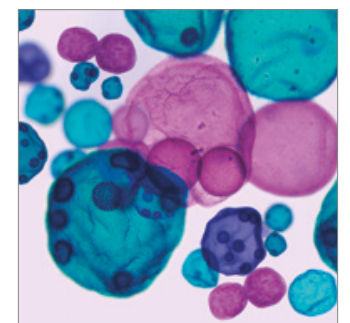

International Journal of Microbiology
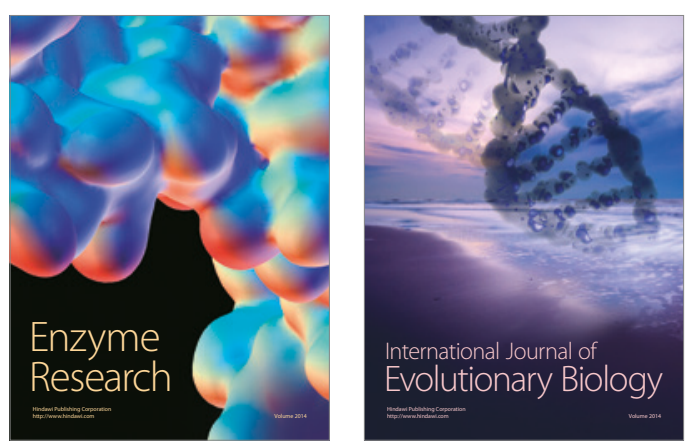
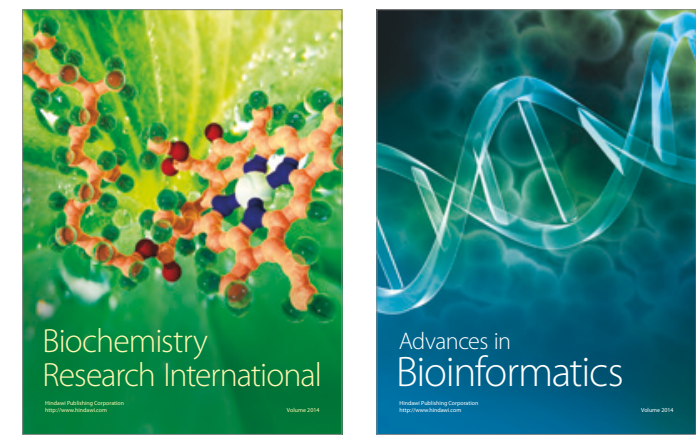

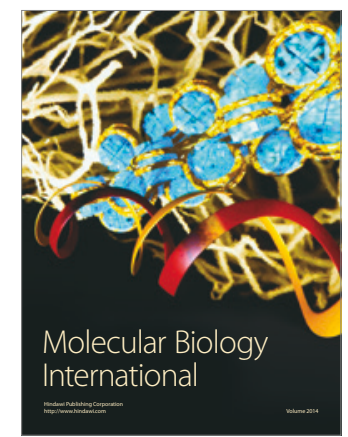

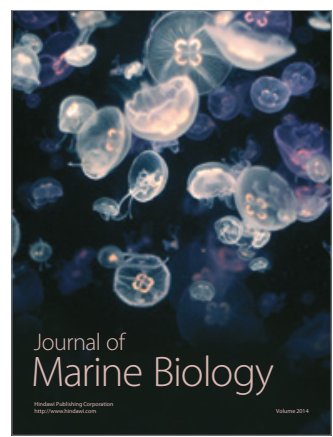

